\title{
Glycolated Thiophene-Tetrafluorophenylene Copolymers for Bioelectronic Applications: Synthesis by Direct Heteroarylation Polymerisation
}

\author{
Zachary S. Parr ${ }^{[a]+}$, Roman Halaksa ${ }^{[a],[b] \dagger}$, Peter A. Finn ${ }^{[a]}$, Reem B. Rashid ${ }^{[c]}$, Alexander Kovalenko ${ }^{[b]}$,
} Martin Weiter ${ }^{[b]}$, Jonathan Rivnay ${ }^{[c]}$, Jozef Krajčovič ${ }^{[b]}$, Christian B. Nielsen ${ }^{[a]^{*}}$

\begin{abstract}
We have designed and synthesised a series of copolymers containing a glycolated 1,4-dithienyl-2,3,5,6-tetrafluorophenylene unit copolymerized with thiophene, bithiophene, thienothiophene and 1,2,4,5-tetrafluorobenzene comonomer units by direct heteroarylation polymerisation. We have investigated the optical, electrochemical, electrochromic and solid-state structural properties of the copolymers. The copolymers exhibit stable redox properties in organic solvents and promising redox properties in thin film configuration with an aqueous electrolyte. Finally, we have assessed the potential of the copolymers as active materials in organic electrochemical transistors (OECTs) finding promising performance as an accumulation mode OECT material with a peak transconductance of $0.17 \mathrm{mS}$ and a good on/off ratio of $10^{5}$ for the thiophene copolymer.
\end{abstract}
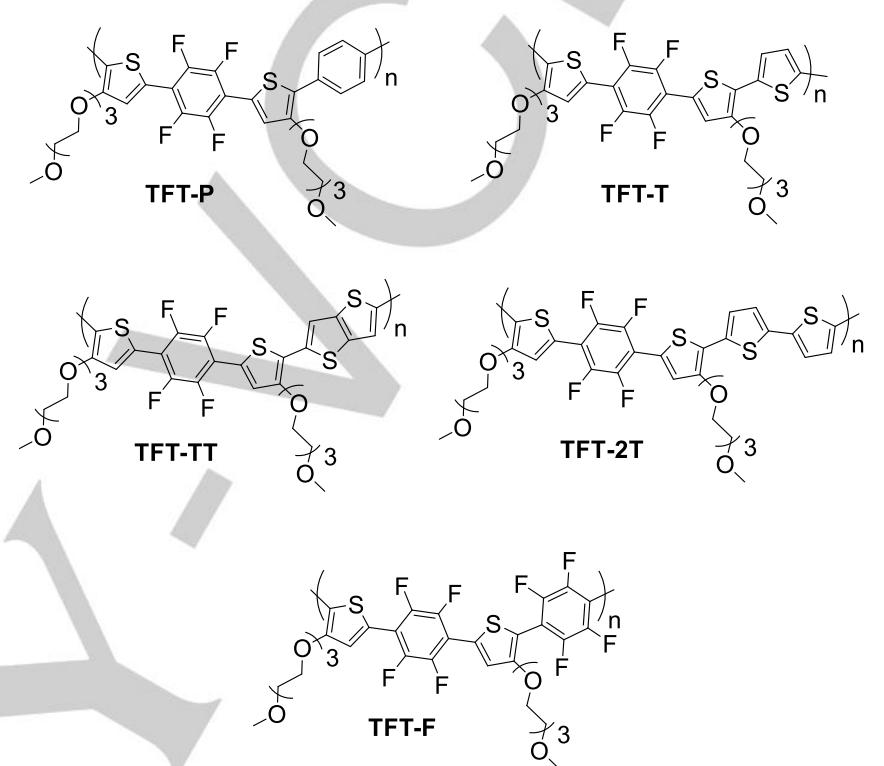

Figure 1 Chemical structures of the synthesised copolymers.

Organic electrochemical transistors (OECTs) are one of the devices most frequently used in organic bioelectronics. They have successfully been used to stimulate neurons ${ }^{[13]}$, record an electrocardiograph ${ }^{[13]}$ and scan muscle activity. ${ }^{[14]}$ The OECT is a three-electrode transistor, which contains an electrolyte through which the active semiconducting layer is gated. ${ }^{[15,16]}$ By applying a voltage to the gate, ions are injected from the electrolyte into the semiconductor film, changing its conductivity ${ }^{[17]}$ while both concentration and nature of the electrolyte ${ }^{[18,19]}$ affect the magnitude of the drain current. ${ }^{[20]}$ Thus, the OECT combines both a direct sensing of ionic species and the inherent transistor amplification of signal in the structure. ${ }^{[21]}$ For p-type operation, OECT active layer materials must be stable in both oxidized and neutral form typically in the presence of an aqueous electrolyte and also have good charge carrier mobility. ${ }^{[22]}$

Improvement of charge carrier mobility and the stability of electroactive compounds is a recent subject of scientific interest, because they are very important properties for the proper function of organic electronic devices. ${ }^{[23,24]}$ Charge carrier mobility is strongly dependent on the assembly of the conjugated backbone, planarity, density of impurities and structural defects. ${ }^{[25-28]}$ From a molecular design point of view, attempts to reduce structural and energetic disorder in conjugated polymers have focused on either covalent or non-covalent strategies towards rigidifying the polymer backbone. ${ }^{[29-31]}$ Previously published work on the 1,4dithienyl-2,3,5,6-tetrafluorophenylene (TFT) motif shows that this building block achieves higher backbone rigidity than 1,4- 


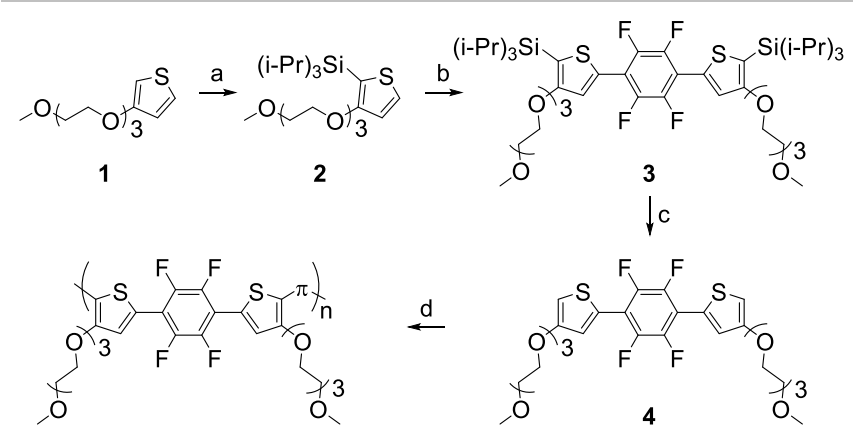

$$
\text { TFT-TT }
$$

functionalised thiophenes (TFT) and either benzene (TFT-P), thiophene (TFT-T), thieno[3,2- $b$ ]thiophene (TFT-TT), bithiophene (TFT-2T) or tetrafluorophenylene (TFT-F), as representatives of conjugated building blocks (Figure 1). The synthetic strategy uses the modified method of direct arylation previously published by Reynolds et al ${ }^{[42]}$, which could be very advantageous for biosensor applications by avoiding particularly toxic reagents and intermediates. Most other previously published cross-coupling methods involving triethyleneglycol functionalised thiophenes use highly toxic stannanes ${ }^{[43,44]}$, or does not allow a selective reaction only in the 5-position of the thiophene ring. ${ }^{[45]}$ Furthermore, we present structural and electronic characterisation of the synthesised copolymers as well as a functioning OECT prepared from the most promising material TFT-T.

\section{Results and Discussion}

\section{Synthesis}

The target polymers were synthesised as depicted in Scheme 1 Molecule 2 was synthesised in a $72 \%$ yield by lithiation of 1 and TFT-2T, TFT-TT and TFT- F: (a) BuLi, THF, $-78^{\circ} \mathrm{C}$, trilsopropylsilyl chloride, (b) 1,4-dibromotetrafluorophenylene, tris(2-methoxyphenyl)phosphine, pivalic acid, $\mathrm{Pd}(\mathrm{OAc})_{2}, \mathrm{Cs}_{2} \mathrm{CO}_{3}$, toluene, $120^{\circ} \mathrm{C}$; (c) TBAF, THF, rt; (d) diBr-m, tris $(2$ methoxyphenyl)phosphine, pivalic acid, $\mathrm{Pd}(\mathrm{OAc})_{2}, \mathrm{Cs}_{2} \mathrm{CO}_{3}$, chlorobenzene, $120^{\circ} \mathrm{C}$.

dithienyl-phenylene ${ }^{[32]}$ due to the push-pull effect as well as possible non-covalent intramolecular F-H and F-S interactions. ${ }^{[3,34]}$ Due to the electron-accepting behaviour of the tetrafluorophenylene unit, both the highest occupied molecular orbital (HOMO) and lowest unoccupied molecular orbital (LUMO) energy of the TFT motif are (compared with non-fluorinated counterparts) shifted to more negative values. This translates for the $\mathrm{HOMO}$ to an increase of the ionisation potential and therefore less susceptibility to irreversible oxidation processes e.g. due to atmospheric oxygen exposure. ${ }^{[33-36]}$ The polymer side chains increase solubility, which is a precondition for solution processability. However, the choice of side chain also greatly affects $\pi-\pi$ stacking and therefore the charge carrier mobility. Incorporation of the triethylene glycol side chains, as chosen in this study, brings a number of advantages. Due to the strong positive mesomeric effect of the oxygen atom attached directly to the thiophene, an increase in the push-pull effect can be expected, resulting in a higher rigidity of the conjugated backbone. Furthermore, in comparison with commonly used alkyl chains, glycol chains are more flexible and possess constant dipole ${ }^{[37]}$; both factors can result in a shortening of the $\pi-\pi$ stacking distance between the polymer backbones. ${ }^{[38,39]}$ Another essential property is that the glycol chains have a high affinity for polar solvents and ions, allowing their penetration from the aqueous electrolyte into the polymer thin film, resulting in the possibility of mixed conduction of both electrical charges and ions in the solid state. ${ }^{[40]}$ Ion conduction is a crucial prerequisite for creating a functioning organic electrochemical transistor (OECT). ${ }^{[41]}$

Adhering to the design criteria discussed above, we have developed a simple synthetic strategy for the preparation of five novel donor-acceptor polymers, which combine in their structure a tetrafluorophenylene unit flanked by triethylene glycol
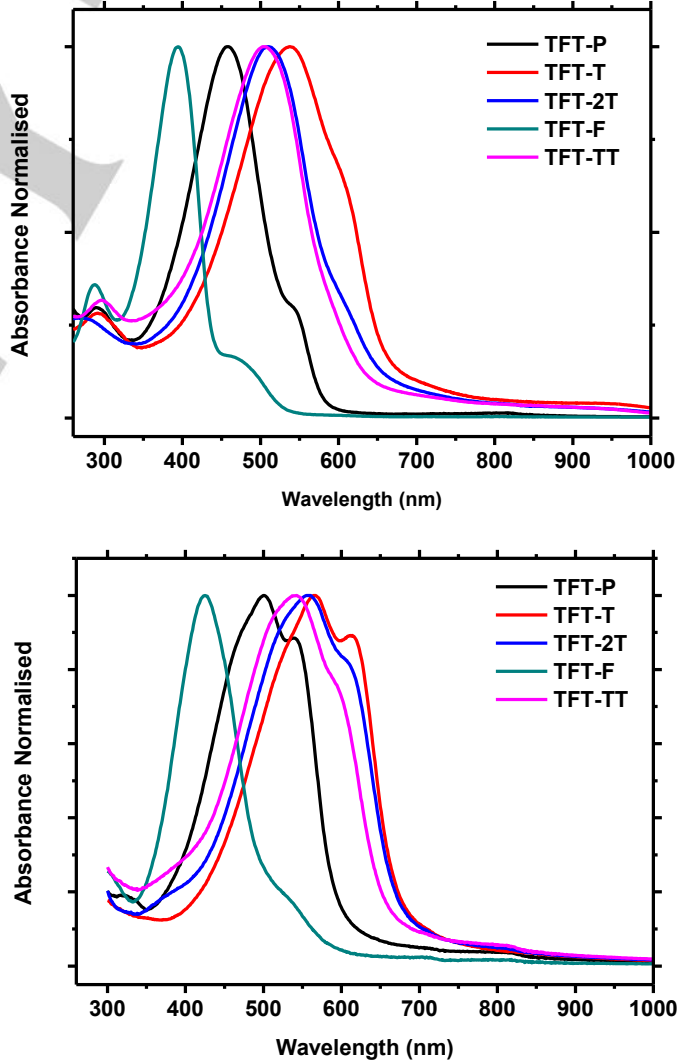

Figure 2 [a] Normalised UV-vis spectra of polymers in chloroform solution and [b] Normalised UV-vis spectra of polymer thin films.

subsequent treatment with triisopropylsilyl chloride. Direct arylation of 2 with 1,4-dibromotetrafluorophenylene gave $\mathbf{3}$ in $67 \%$ yield and was subsequently treated with TBAF in order to give $\mathbf{4}$ in $88 \%$ yield. Molecule $\mathbf{4}$ was finally polymerised by direct arylation with 1,4-dibromobenzene, 2,5-dibromothiophene, 5,5'- 
Table 1. Optical properties of the polymers in solution and thin film.

\begin{tabular}{ccccc}
\hline Polymer & $\begin{array}{c}\lambda_{\max } \\
\text { Solution } \\
{[\mathrm{nm}]}\end{array}$ & $\begin{array}{c}\lambda_{\max } \\
\text { Film } \\
{[\mathrm{nm}]}\end{array}$ & $\begin{array}{c}\text { Optical } \\
\text { Band } \\
\text { Gapic] } \\
{[\mathrm{eV}]}\end{array}$ & $\begin{array}{c}\text { Onset of } \\
\text { absorption } \\
{[\mathrm{nm}]}\end{array}$ \\
\hline TFT-P & 458 & 501 & 2.08 & 596 \\
TFT-T & 538 & 566 & 1.84 & 675 \\
TFT-2T & 509 & 556 & 1.83 & 676 \\
TFT-F & 394 & 425 & 2.44 & 508 \\
TFT-TT & 504 & 543 & 1.88 & 660 \\
\hline
\end{tabular}

[a] UV-vis measured in chloroform solution. [b] Thin film spin coated from chloroform solution at $5 \mathrm{mg} / \mathrm{ml}$ onto glass slide. [c] Optical band gap estimated from onset of absorption in thin film UV-vis.

dibromo-2,2'-bithiophene, 1,4-dibromotetrafluorobenzene and 2,5-dibromothieno[3,2-b]thiophene to afford the target polymers TFT-P $\left(28 \%\right.$ yield, $\left.\mathrm{M}_{\mathrm{n}} 7.3 \mathrm{KDa}\right)$, TFT-T $\left(77 \%\right.$ yield, $\left.\mathrm{M}_{\mathrm{n}} 8.7 \mathrm{KDa}\right)$ TFT-TT (12\% yield), TFT-2T ( $21 \%$ yield, $\mathrm{M}_{\mathrm{n}} 9.6 \mathrm{KDa}$ ) and TFTF $\left(51 \%\right.$ yield, $\left.M_{n} 10.1 \mathrm{KDa}\right)$, respectively. All the crude polymers were precipitated into hexane and washed in a Soxhlet thimble with hexane, acetone and methanol before the final polymers were extracted with chloroform. We note that a reliable molecular weight could not be measured for TFT-TT, most likely due to strong aggregation in solution, whereas the other polymers exhibited moderate molecular weights as determined by gel permeation chromatography. Thermal characterisation of the polymers carried out by thermogravimetric analysis showed $5 \%$ mass loss for: TFT-P at $259^{\circ} \mathrm{C}$, TFT-T at $300^{\circ} \mathrm{C}$, TFT-2T at 358 ${ }^{\circ} \mathrm{C}$, TFT-F at $342{ }^{\circ} \mathrm{C}$, and TFT-TT at $317^{\circ} \mathrm{C}$.

\section{Optical Properties}

Initial characterisation of the polymers was carried out by UV-vis spectroscopy (Figure 2a) in chloroform solution. The polymers absorb strongly in the visible range with colours ranging from yellow into deep purple in solution; results are summarised in Table 1. The most red-shifted spectrum was observed for TFT-T having a $\lambda_{\max }$ at $538 \mathrm{~nm}$ with a significant shoulder observed for this polymer at around $610 \mathrm{~nm}$. Increasing thiophene content resulted in a slight blue-shift in absorbance for TFT-2T and TFTTT with $\lambda_{\max }$ of $509 \mathrm{~nm}$ and $504 \mathrm{~nm}$ respectively with both polymers exhibiting a less intense shoulder around $610 \mathrm{~nm}$ and $600 \mathrm{~nm}$ respectively. The optical absorption of the less electron rich phenyl copolymer TFT-P was further blue-shifted with a $\lambda_{\max }$ at $458 \mathrm{~nm}$ while the absorption feature of the most electron deficient polymer TFT-F was significantly blue-shifted to $\lambda_{\max } 425$ $\mathrm{nm}$, appearing almost yellow in solution. The latter two polymers still exhibit small low-energy shoulders which may be weakly absorbing intrachain charge transfer transitions from the weak donor acceptor nature of these polymers as displayed by the DFT data discussed later in this text. Thin film UV-vis spectra (Figure 2b) of spin coated films on glass slides showed a similar trend in absorption with the TFT-T copolymer exhibiting the most redshifted $\lambda_{\max }$ at $566 \mathrm{~nm}$, shifted by $28 \mathrm{~nm}$ from solution, followed by TFT-2T which showed the most significant red-shift between solution and film of $47 \mathrm{~nm}$. TFT-TT and TFT-P exhibited absorption maxima at $543 \mathrm{~nm}$ and $501 \mathrm{~nm}$, respectively, in both cases a $43 \mathrm{~nm}$ red-shift compared to solution. Similar to solution data, TFT-F was significantly blue-shifted with $\lambda_{\max }$ at $425 \mathrm{~nm}$, in agreement with the DFT data discussed below. Optical band gaps were determined from the onset of absorption for each of the polymer thin films and were narrowest for TFT-T, TFT-2T and TFT-TT at 1.83-1.88 eV with TFT-P and TFT-F having wider band gaps at $2.04 \mathrm{eV}$ and $2.44 \mathrm{eV}$ respectively. The observed strong red-shift of TFT-T compared with TFT-P is caused by the more electron rich polymer backbone and therefore a shallower HOMO
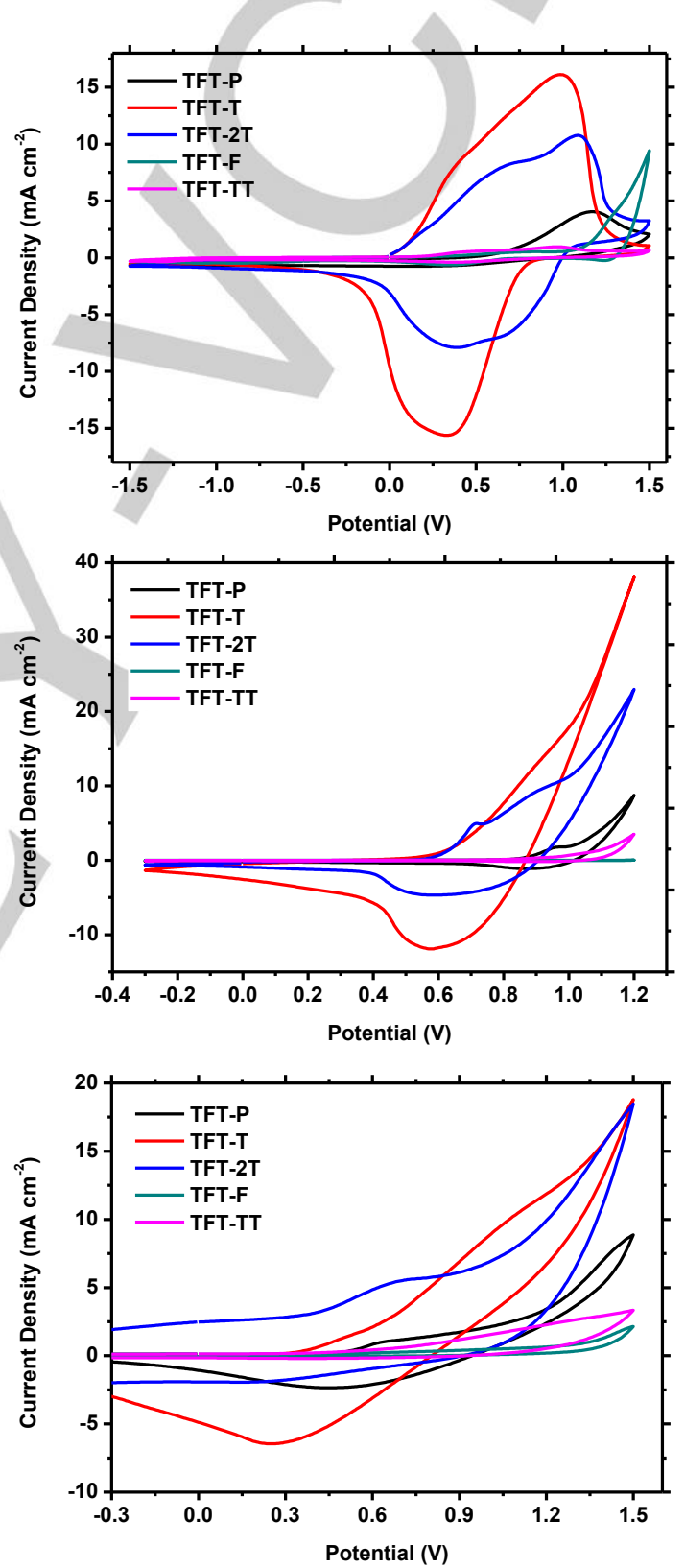

Figure 3 Cyclic voltammetry of drop cast polymer thin films on glassy carbon electrode with a scan rate of $100 \mathrm{mV} \mathrm{s}^{-1}$ in [a] $0.1 \mathrm{M} \mathrm{TBAPF}_{6}$ in acetonitrile, [b] $0.1 \mathrm{M} \mathrm{NaCl}$ in $\mathrm{H}_{2} \mathrm{O}$, and [c] $0.1 \mathrm{M} \mathrm{KPF}_{6}$ in $\mathrm{H}_{2} \mathrm{O}$.

level and a narrower band gap. The widest optical band gap of $2.44 \mathrm{eV}$ for TFT-F despite the increased acceptor content for this polymer correlates with an increased torsion angle calculated in 
Table 2. Electrochemical properties of polymer thin films

\begin{tabular}{lllll}
\hline Polymer & $\begin{array}{l}\mathrm{E}_{\text {onset }^{[\mathrm{a}]}} \\
{[\mathrm{V}]}\end{array}$ & $\begin{array}{l}\mathrm{E}_{1 / 2}[\mathrm{a}] \\
{[\mathrm{V}]}\end{array}$ & $\begin{array}{l}\mathrm{IP}^{[\mathrm{b}]} \\
{[\mathrm{eV}]}\end{array}$ & $\begin{array}{l}\mathrm{EA}^{[\mathrm{c}]} \\
{[\mathrm{eV}]}\end{array}$ \\
\hline TFT-P & 0.55 & 0.58 & 5.65 & 3.57 \\
TFT-T & -0.02 & 0.55 & 5.08 & 3.24 \\
TFT-2T & -0.07 & 0.46 & 5.03 & 3.20 \\
TFT-F & 0.99 & - & 6.09 & 3.65 \\
TFT-TT & -0.10 & 0.35 & 5.00 & 3.12 \\
\hline
\end{tabular}

[a] Thin film cyclic voltammetry performed on glassy carbon electrode with $0.1 \mathrm{M}$ tetrabutylammonium hexafluorophosphate in acetonitrile supporting electrolyte versus $\mathrm{E}_{1 / 2}$ of $\mathrm{Fe} / \mathrm{Fe}^{+}$redox couple determined to be $0.11 \mathrm{~V}$. All values reported are for second cycle and scan rate of $100 \mathrm{mV} \mathrm{s}^{-1}[\mathrm{~b}] \mathrm{IP}$ estimated from Eonset according to Cardona ${ }^{[46]}[\mathrm{c}]$ Electron affinity determined from optical band gap and ionisation potential.

the DFT of $36^{\circ}$ meaning the orbital energies in this polymer are much less delocalized (SI section 8.0).

\section{Electrochemical Characterization}

Measurement of oxidative and reductive electrochemical properties of the polymers was carried out initially by cyclic voltammetry $(\mathrm{CV})$ in thin film configuration. Polymer thin films were drop cast from chloroform onto a glassy carbon working electrode with a $\mathrm{Ag} / \mathrm{Ag}^{+}$reference electrode, platinum wire counter electrode and $0.1 \mathrm{M}$ tetrabutylammonium hexafluorophosphate $\left(\mathrm{TBAPF}_{6}\right)$ in acetonitrile as the supporting electrolyte (Figure 3a). The polymers all exhibited some degree of pseudo-reversible oxidation in this configuration with values summarised in Table 2. The onset of oxidation could be determined for each polymer allowing for an estimation of the ionisation potential (IP) according to the method described by Cardona. ${ }^{[46]}$ The IP values determined for TFT-T, TFT-2T and TFT-TT are broadly similar at approximately 5.00-5.08 eV. TFT-P and in particular TFT-F exhibited a much-increased ionisation

Table 3. Electrochemical properties of polymer thin films in aqueous electrolyte

\begin{tabular}{lll}
\hline Polymer & $\begin{array}{l}E_{\text {onset }} \mathrm{NaCl}^{[\mathrm{a}]} \\
{[\mathrm{V}]}\end{array}$ & $\begin{array}{l}\mathrm{E}_{\text {onset }} \mathrm{KPF}_{6}^{[\mathrm{b}]} \\
{[\mathrm{V}]}\end{array}$ \\
\hline TFT-P & 0.86 & 0.48 \\
TFT-T & 0.65 & 0.33 \\
TFT-2T & 0.61 & 0.10 \\
TFT-F & - & - \\
TFT-TT & 0.76 & 0.57 \\
\hline
\end{tabular}

[a] Thin film cyclic voltammetry performed on glassy carbon electrode with $0.1 \mathrm{M} \mathrm{NaCl}$ in $\mathrm{H}_{2} \mathrm{O}$ supporting electrolyte versus $\mathrm{Ag} / \mathrm{Ag}^{+}$. All values reported are for second cycle and scan rate of $100 \mathrm{mV} \mathrm{s}^{-1}[\mathrm{~b}]$ Thin film cyclic voltammetry performed on glassy carbon electrode with $0.1 \mathrm{M} \mathrm{KPF}_{6}$ in $\mathrm{H}_{2} \mathrm{O}$ supporting electrolyte versus $\mathrm{Ag} / \mathrm{Ag}^{+}$. All values reported are for second cycle and scan rate of $100 \mathrm{mV} \mathrm{s}^{-1}$. potential as a result of the reduced electron richness of the phenylene and tetraphenylene moieties. Further, a reduced excited state stabilisation and quinoidal character exhibited by the latter as a result of backbone torsion yields a considerably higher IP. It is noteworthy that none of the polymers showed evidence of reduction events in a reasonable electrochemical window for OECT operation.

To obtain insight into the electrochemical behaviour of the polymers in a configuration more relevant to bioelectronic applications, thin film $\mathrm{CV}$ was performed with an aqueous $0.1 \mathrm{M}$ $\mathrm{NaCl}$ solution as the electrolyte (Table 3 ). A reversible oxidation process could be observed in the positive regime only for TFT-T (Figure 3 and SI section 7.0) with the onset of oxidation shifted to a considerably more positive value of $0.65 \mathrm{~V}$ versus $\mathrm{Ag} / \mathrm{Ag}^{+}$

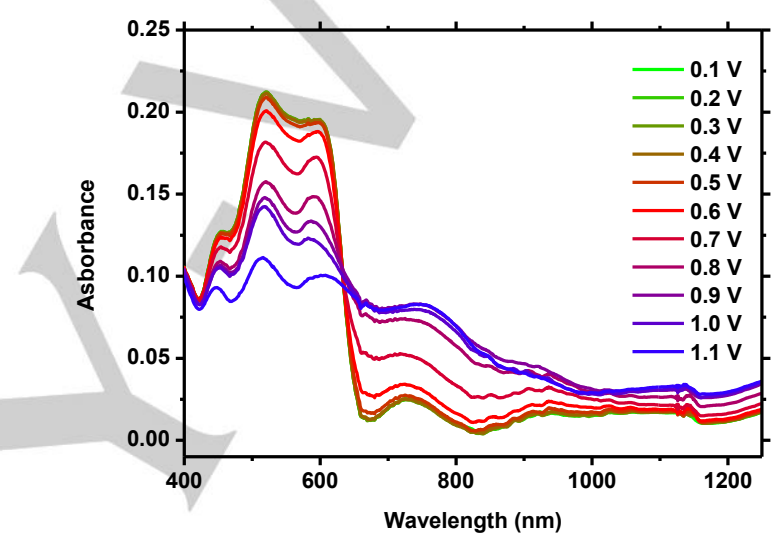

Figure 4 Thin film spectroelectrochemistry of TFT-T on ITO glass with $0.1 \mathrm{M}$ $\mathrm{NaCl}$ in $\mathrm{H}_{2} \mathrm{O}$ as supporting electrolyte.

compared to acetonitrile $\mathrm{TBAPF}_{6}$ supporting electrolyte. Cyclic voltammograms for TFT-2T, TFT-TT and TFT-P exhibited irreversible oxidation with rapid film degradation after a few scans, while TFT-F could not be oxidised within the electrochemical window. The measured onsets of oxidation followed a similar trend to those observed in acetonitrile $\mathrm{TBAPF}_{6}$ electrolyte. The increased glycol side chain density of TFT-T per unit length of polymer compared to TFT-TT and TFT-2T likely contributes to the reversible oxidation and increased ion injection evident from the higher current density. ${ }^{[4]}$ Under identical drop casting conditions for all polymers, the thiophene and bithiophene copolymers show significantly higher current densities than any of the other polymers (Figure 3b).

It has been shown that the size of the hydration shell of the anion affects the potential and kinetics of ion injection during electrochemical switching of glycolated polymers in an aqueous environment. ${ }^{[19]}$ Cyclic voltammetry was therefore also carried out using a $0.1 \mathrm{M} \mathrm{KPF}_{6}$ aqueous supporting electrolyte (Figure $3 \mathrm{c}$, Table 3 and SI section 7.0). In comparison to the chloride anion, the hexafluorophosphate anion is found to have a much smaller hydration shell, which could facilitate easier ion penetration. A 
significant decrease in the onset of oxidation, on the order of 20$50 \mathrm{mV}$, was observed: $0.48 \mathrm{~V}$ for TFT-P, $0.33 \mathrm{~V}$ for TFT-T and $0.10 \mathrm{~V}$ for TFT-2T with the thiophene copolymer showing the highest degree of electrochemical reversibility. The reduction in oxidation potentials are consistent with the values observed for other ion conducting polymers. ${ }^{[48]}$

Subsequently, the most promising polymer, TFT-T, was subject to thin film spectroelectrochemistry to examine polaron formation and whether the entire thin film could be oxidised in an aqueous electrolyte. Thin films were spun on ITO-coated glass substrates from a $5 \mathrm{mg} / \mathrm{ml}$ chloroform solution, submerged in 0.1 $\mathrm{M} \mathrm{NaCl}$ solution in a spectroelectrochemical cell and subsequently oxidised using a stepwise increase in voltage (Figure 4). Gradual formation of the polaron can be observed for TFT-T around $750 \mathrm{~nm} \mathrm{~nm}$ with concurrent quenching of the $\pi-\pi^{*}$ transition at 566 and $615 \mathrm{~nm}$, which is in good agreement with spectroelectrochemical analysis of related polythiophenes. ${ }^{[43]}$ The polaronic absorption band reaches a maximum in intensity at 0.9 $\mathrm{V}$ followed by a subsequent depletion when the potential is increased further to $1.2 \mathrm{~V}$ which is beyond operating parameters for OECTs due to electrolysis of water occurring at $1.23 \mathrm{~V}$. In agreement with the CV data, it can be seen from spectroelectrochemistry that oxidation starts to occur for TFT-T around $0.5 \mathrm{~V}$ as the $\pi-\pi^{*}$ transition begins to bleach. From spectroelectrochemistry it is also clear that a significant proportion of the thin film oxidises when going from 0.5 to $0.9 \mathrm{~V}$, which is promising for OECT operation.

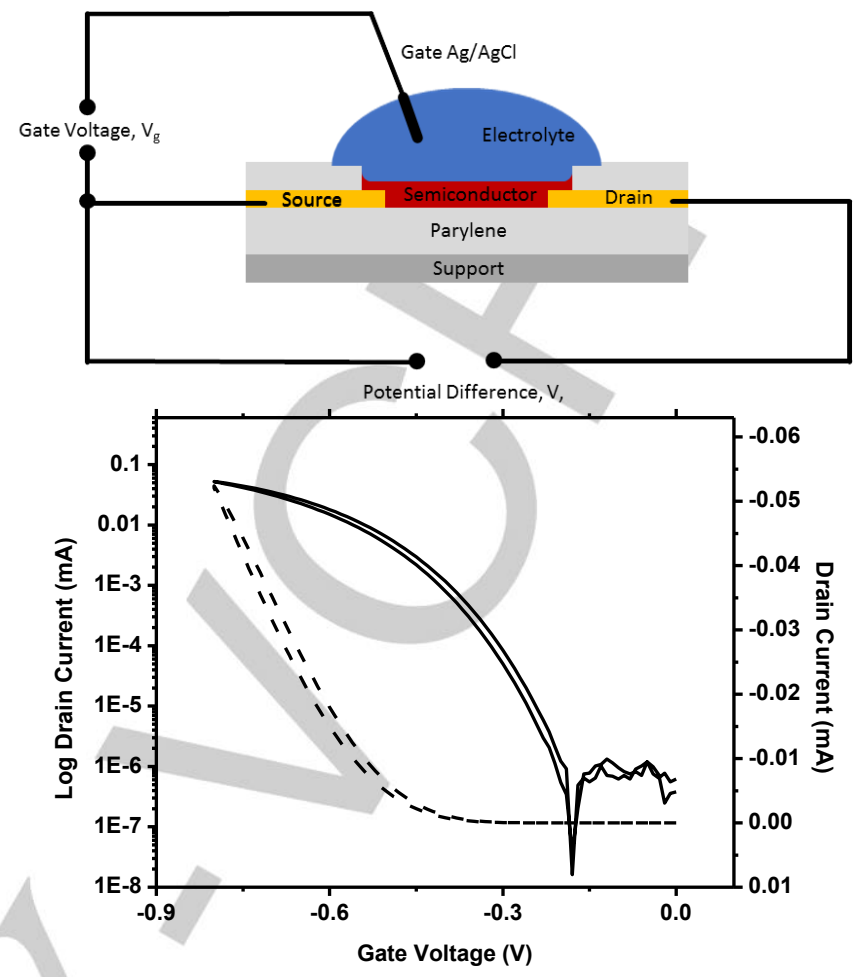

a markedly shorter distance between polymer chains in comparison to TFT-T. The conformational lock arising from

\section{Structural Properties}

Wide angle X-ray diffraction was carried out to investigate the solid-state structural ordering of the polymers; results are summarised in Table 4. Lamellar stacking diffractions (100) could be observed for all polymers with exception of TFT-TT which appeared amorphous under these experimental conditions. Lamellar d-spacings were found to be between $13.54 \AA$ and 15.02 A. The shortest lamellar staking distance of $13.54 \AA$ was observed for TFT-2T likely as a result of the bithiophene comonomer affording a linear backbone with side chains being equally distributed on both sides of the polymer chain (assuming all-trans conformation of thiophenes along the polymer backbone) allowing

Table 4. X-ray diffraction data of polymer films and torsion angles from DFT.

\begin{tabular}{|c|c|c|}
\hline Polymer & $\begin{array}{l}\text { Lamellar Stacking }^{[\mathrm{a}]} \\
\qquad[\AA]\end{array}$ & $\begin{array}{c}\text { Torsion Angle } \mathrm{e}^{[\mathrm{b}]} \\
{\left[{ }^{\circ}\right]}\end{array}$ \\
\hline TFT-P & 14.10 & 0.2 \\
\hline TFT-T & 15.02 & 1.5 \\
\hline TFT-2T & 13.54 & 0.5 \\
\hline TFT-F & 14.24 & 36 \\
\hline TFT-TT & - & 0.4 \\
\hline
\end{tabular}

[a] X-ray diffraction carried out on films prepared on Si substrates by drop casting a $5 \mathrm{mg} / \mathrm{ml}$ solution in ortho-dichlorobenzene allowed to slowly evaporate under $\mathrm{N}_{2}$. [b] DFT calculations carried out using B3LYP with 6$311 \mathrm{G}^{\star *}$ basis set.

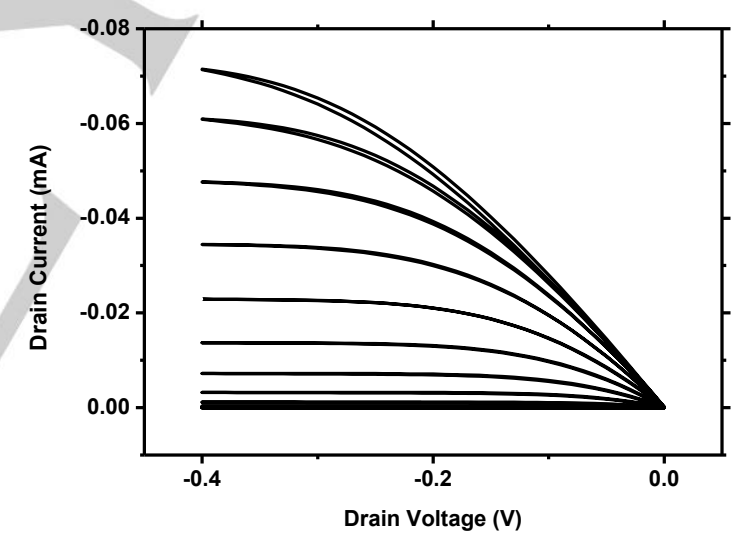

Figure 5 [a] Cross section organic electrochemical transistor used for characterisation [b] Log transfer curve (solid line) at source drain delay $0.2 \mathrm{~s}, \mathrm{~V}_{\mathrm{d}}$ $-0.4 \mathrm{~V}$ with linear transfer curve (dotted line) [c] Output curve in $50 \mathrm{mV}$ gate potential steps for TFT-T based OECT.

attractive S-O interactions between the glycol side chain and the adjacent thiophene unit results, for TFT-T, in side chains being sequentially syn and a slight backbone curvature due to the bond angle of the thiophene. The TFT-T polymer consequently displays less efficient packing of side chains and more steric hindrance along the backbone giving rise to a longer lamellar stacking. ${ }^{[49]}$ The phenylene copolymers, TFT-P and TFT-F, with lamellar distances of 14.10 - $14.24 \AA$ can adopt more linear backbones due to the linear nature of the phenylene units with side chains arranged anti with respect to each other and therefore more ordered packing and shorter lamellar distance in the solid state. No diffraction peaks relating to $\pi$-stacking were observed for any of the polymers, most likely due to a preferential edge-on 
orientation of polymer chains on the substrate during thin film deposition. It is also worth noting that many low crystallinity polymers nevertheless have shown good performance in OFETs. ${ }^{[31]}$

Density functional theory calculations carried out suggest highly coplanar backbones with low torsion angles measured along the S-C-C-F dihedral between $0.2^{\circ}$ and $1.5^{\circ}$ as a result of planarising interactions between sulphur and fluorine and oxygen atoms (SI section 8.0). An exception to this observation was TFT$\mathbf{F}$, which was calculated to have a torsional angle of $36^{\circ}$ likely as a result of steric hindrance and coulombic repulson between the fluorine and oxygen atoms on adjacent glycolated thiophene and tetrafluorophenylene units leading to a very twisted backbone. This is expected to be detrimental to charge transport as well as interchain charge transport in the $\pi$-stacking direction.

\section{Transistor Characterisation}

Aqueous electrochemical stability and reversibility are critical requirements for OECT operation. As discussed above, we observed the most promising electrochemical stability in aqueous for TFT-T which showed very little degradation compared to the other polymers, all of which showed significant loss of redox activity after less than five cycles (SI section 7.0). Further, with spectroelectrochemistry, we were able to demonstrate growth of polaron absorption bands similar to those observed for g2T-T. ${ }^{[43]}$ In order to assess the applicability of this material to bioelectronics TFT-T was tested as the active material of an OECT (SI 10.0 Figure 5a). The polymer was spin-coated onto a sacrificial parylene coated prefabricated substrate from a $5 \mathrm{mg} / \mathrm{ml}$ chloroform solution with $100 \mu \mathrm{m} \times 10 \mu \mathrm{m}$ channel dimensions with gold source and drain electrodes and silver wire gate electrode in contact with $0.1 \mathrm{M} \mathrm{NaCl}$ droplet (device architecture is shown in Figure $5 \mathbf{a}$ as reported by Rivnay et al[50]). Representative device characteristics are shown in Figure $\mathbf{5 b}$ and Figure $\mathbf{5 c}$ illustrating transfer and output curves respectively with the device characteristics recorded after three cycles of the device to ensure repeatability and stability. TFT-T functions in the accumulation regime as a $p$-type OECT material with a threshold voltage $\left(V_{t}\right)$ at $-0.38 \mathrm{~V}$; a peak drain current $\left(\mathrm{I}_{\mathrm{d}}\right)$ of $71 \mu \mathrm{A}$; an on/off ratio of $1 \times 10^{5}$ and a transconductance $\left(\mathrm{g}_{\mathrm{m}}\right)$ of $0.17 \mathrm{mS}$ for a drain voltage $\left(\mathrm{V}_{\mathrm{d}}\right)$ of $-0.4 \mathrm{~V}$; a gate voltage of $-0.75 \mathrm{~V}$ and a source drain delay of $0.2 \mathrm{~s}$. The measured transconductance, which is averaged over three devices and extracted from the maximum slope of the transfer curve $\left(g_{m}=d l_{d} / d N_{g}\right)$, for an average device thickness measured to be $43 \mathrm{~nm}$ by profilometry, is of a similar magnitude to values extracted for previously reported benzodithiophenebased materials ${ }^{[43]}$ and within operating parameters for a biointerfacing device. The $\mu \mathrm{C}^{*}$ product $(\mu$ being the electronic carrier mobility and $C^{*}$ being the capacitance of the channel per unit volume), used for benchmarking organic mixed conductors, was found to be $10 \mathrm{~F} \mathrm{~cm}^{-1} \mathrm{~V}^{-1} \mathrm{~s}^{-1}$ calculated from the average value of peak $g_{m}$ and $W d / l$ using the OECT equation in saturation regime. ${ }^{[51]}$ This value is comparable to that of several PEDOT and thiophene-based mixed conductors evaluated recently. ${ }^{[51]}$ Reasonably low hysteresis was observed which was found to be somewhat dependent on source drain delay. When the materials were pushed to higher $\mathrm{V}_{\mathrm{g}}$, we observed a breakdown of the material at $>-0.8 \mathrm{~V}$ and a reduction in performance. Nor do we observe improved performance with $V_{d}>-0.4 \mathrm{~V}$. These results correlate well with $\mathrm{CV}$ and spectroelectrochemistry data and suggest that complete bleaching of the $\pi-\pi^{*}$ transition observed in the spectroelectrochemistry above $0.9 \mathrm{~V}$ is due to material decomposition. The OECT results are promising given the relatively low molecular weight of TFT-T likely limiting the charge carrier mobility.

\section{Conclusions}

A series of five novel glycolated dithienyl-tetrafluorophenylene copolymers were synthesised and structurally characterized. We show reversible redox properties for polymer thin film versus aqueous and organic solvents as a result of addition of glycol side chain enabling mixed ionic and electronic conductivity. We observe oxidation potentials slightly higher than those reported previously for glycolated polythiophenes as a result of the electron-deficient tetrafluorophenylene constituent of the polymers, though not as high as the potential required to electrochemically dope unmodified P3HT. ${ }^{[43,52]}$ We observe efficient ion injection into the polymer thin films despite some resistance to ion injection as a result of the large hydration shell of the chloride anion and some considerable first cycle memory ${ }^{[53]}$. In CV experiments with $0.1 \mathrm{M} \mathrm{KPF}_{6}$ aqueous supporting electrolyte we observe considerably reduced ionisation potential for the polymers in comparison to $\mathrm{NaCl}$ supporting electrolyte, comparable to the trends previously observed for conducting polymers. ${ }^{[19]}$ The thiophene copolymer TFT-T was demonstrated to have good electrochromic properties in aqueous supporting electrolyte with bleaching of the $\pi-\pi^{*}$ transition beginning at around $0.5 \mathrm{~V}$, consistent with operating conditions for an OECT. We observe reasonable stability in cyclic voltammetry, and further improvements of polymer molecular weights will undoubtedly afford more stable materials. Finally, we examine the most promising material, TFT-T, as the active channel in an organic electrochemical transistor. We observe stable hysteresis-free operation with a maximum transconductance value of $0.17 \mathrm{mS}$, for a device of $\mathrm{Wd} / \mathrm{l}$ of $3.9 \times 10^{2} \mathrm{~nm}$ and a $\mu \mathrm{C}^{*}$ value of $10 \mathrm{~F} \mathrm{~cm}^{-1}$ $\mathrm{V}^{-1} \mathrm{~s}^{-1}$ averaged across the devices. The performance of TFT-T as the active material in an OECT is thus comparable to that of recently published glycolated benzodithiophene polymers.

\section{Experimental Section}

For full characterisation, synthetic procedures, spectroscopic data, X-ray diffractograms and computational data see supporting information.

\section{Acknowledgements}

The authors acknowledge the Academy of Medical Sciences \& Wellcome Trust (SBF002/1158), the Czech Science Foundation (project 17-24707S) and the Materials Research Institute for financial support. The authors thank Dr. Michal Kalina for GPC measurements.

Keywords: direct heteroarylation $\cdot$ organic electrochemical transistors $\cdot$ polymerisation $\bullet$ semiconductors $\bullet$ thiophenes 
[1] R. Xue, J. Zhang, Y. Li, Y. Li, Small 2018, 14, 1-24.

[2] J. Tagare, S. Vaidyanathan, J. Mater. Chem. C 2018, 6, 10138-10173.

[3] W. Tang, Y. Huang, L. Han, R. Liu, Y. Su, X. Guo, F. Yan, J. Mater. Chem. C 2019, 7, 790-808.

[4] T. Hodsden, I. McCulloch, A. F. Paterson, K. J. Fallon, H. Bronstein, Y. Han, M. Heeney, T. D. Anthopoulos, B. C. Schroeder, S. Singh, Adv. Mater. 2018, 30, 1801079.

[5] J. Borges-González, C. J. Kousseff, C. B. Nielsen, J. Mater. Chem. C 2019, 7, 1111-1130.

[6] S. Inal, J. Rivnay, A.-O. Suiu, G. G. Malliaras, I. McCulloch, Acc. Chem. Res. 2018, 51, 1368-1376.

[7] J. Rivnay, S. Inal, A. Salleo, R. M. Owens, M. Berggren, G. G. Malliaras, Nat. Rev. Mater. 2018, 3, 17086.

[8] A. Williamson, A. Kaszas, G. G. Malliaras, I. Vanzetta, B. Rózsa, A. Slézia, C. Bernard, M. J. Donahue, G. F. Turi, G. Katona, Eneuro 2018, 5, ENEURO.0187-18.2018.

[9] A. Savva, A. Giovannitti, I. P. Maria, D. Ohayon, J. Rivnay, I. McCulloch, I. Uguz, S. Inal, A. M. Pappa, R. M. Owens, Sci. Adv. 2018, 4, eaat0911.

[10] A. Williamson, J. Rivnay, L. Kergoat, A. Jonsson, S. Inal, I. Uguz, M. Ferro, A. Ivanov, T. A. Sjöström, D. T. Simon, M. Berggren, G. G. Malliaras, C. Bernard, Adv. Mater. 2015, 27, 3138-3144.

[11] I. del Agua, C. M. Proctor, C. Bernard, A. Williamson, A. Slézia, A. Kaszas, A. Ghestem, G. G. Malliaras, A.-M. Pappa, Sci. Adv. 2018, 4, eaau1291.

[12] T. Someya, Z. Bao, G. G. Malliaras, Nature 2016, 540 379-385.

[13] A. Williamson, M. Ferro, P. Leleux, E. Ismailova, A. Kaszas, T. Doublet, P. Quilichini, J. Rivnay, B. Rõzsa, G. Katona, C. Bernard, G. G. Malliaras, Adv. Mater. 2015, 27, 4405-4410.

[14] A. Campana, T. Cramer, D. T. Simon, M. Berggren, F. Biscarini, Adv. Mater. 2014, 26, 3874-3878.

[15] W. Lee, D. Kim, J. Rivnay, N. Matsuhisa, T. Lonjaret, T. Yokota, H. Yawo, M. Sekino, G. G. Malliaras, T. Someya, Adv. Mater. 2016, 28, 9722-9728.

[16] S. H. Kim, K. Hong, W. Xie, K. H. Lee, S. Zhang, T. P. Lodge, C. D. Frisbie, Adv. Mater. 2013, 25, 1822-1846.

[17] D. A. Bernards, G. G. Malliaras, Adv. Funct. Mater. 2007, 17, 3538-3544.

[18] C. Cendra, A. Giovannitti, A. Savva, V. Venkatraman, I. Mcculloch, A. Salleo, S. Inal, J. Rivnay, 2019, 1807034, 111.

[19] L. Q. Flagg, R. Giridharagopal, J. Guo, D. S. Ginger, Chem. Mater. 2018, 30, 5380-5389.

[20] A. Sekar, F. Soavi, P. Kumar, S. Zhang, F. Cicoira, Z. Yi, Appl. Phys. Lett. 2015, 107, 053303.

[21] D. Khodagholy, J. Rivnay, M. Sessolo, M. Gurfinkel, P. Leleux, L. H. Jimison, E. Stavrinidou, T. Herve, S. Sanaur, R. M. Owens, G. G. Malliaras, Nat. Commun. 2013, 4, 1-6.

[22] H. Sun, J. Gerasimov, M. Berggren, S. Fabiano, J. Mater. Chem. C 2018, 6, 11778-11784.

[23] M. Nikolka, G. Schweicher, J. Armitage, I. Nasrallah, C. Jellett, Z. Guo, M. Hurhangee, A. Sadhanala, I. McCulloch, C. B. Nielsen, H. Sirringhaus, Adv. Mater. 2018, 30,
1801874

[24] A. Giovannitti, K. J. Thorley, C. B. Nielsen, J. Li, M. J. Donahue, G. G. Malliaras, J. Rivnay, I. McCulloch, Adv. Funct. Mater. 2018, 28, 1706325.

[25] J. Mei, Y. Diao, A. L. Appleton, L. Fang, Z. Bao, J. Am. Chem. Soc. 2013, 135, 6724-6746.

[26] O. D. Jurchescu, J. Baas, T. T. M. Palstra, Appl. Phys. Lett. 2004, 84, 3061-3063.

[27] R. García, J. Calbo, R. Viruela, M. Á. Herranz, E. Ortí, N. Martín, Chempluschem 2018, 83, 300-307.

[28] M. B. Goldey, D. Reid, J. de Pablo, G. Galli, Phys. Chem. Chem. Phys. 2016, 18, 31388-31399.

[29] D. Venkateshvaran, M. Nikolka, A. Sadhanala, V. Lemaur, M. Zelazny, M. Kepa, M. Hurhangee, A. J. Kronemeijer, V. Pecunia, I. Nasrallah, I. Romanov, K. Broch, I. McCulloch, D. Emin, Y. Olivier, J. Cornil, D. Beljonne, H. Sirringhaus, Nature 2014, 515, 384-388.

[30] H. Chen, M. Hurhangee, M. Nikolka, W. Zhang, M. Kirkus, M. Neophytou, S. J. Cryer, D. Harkin, P. Hayoz, M. AbdiJalebi, C. R. McNeill, H. Sirringhaus, I. McCulloch, Adv. Mater. 2017, 29, 1-6.

[31] M. Nikolka, I. Nasrallah, B. Rose, M. K. Ravva, K. Broch, A. Sadhanala, D. Harkin, J. Charmet, M. Hurhangee, A. Brown, S. Illig, P. Too, J. Jongman, I. McCulloch, J.-L. Bredas, H. Sirringhaus, Nat. Mater. 2017, 16, 356-362.

[32] S. Lois, J. C. Florès, J. P. Lère-Porte, F. Serein-Spirau, J. J. E. Moreau, K. Miqueu, J. M. Sotiropoulos, P. Baylère, M. Tillard, C. Belin, European J. Org. Chem. 2007, 40194031.

[33] D. J. Crouch, P. J. Skabara, M. Heeney, I. McCulloch, S. J. Coles, M. B. Hursthouse, Chem. Commun. 2005, 0, 1465.

[34] P. Sonar, J. Chang, Z. Shi, J. Wu, J. Li, J. Mater. Chem. C 2015, 3, 2080-2085.

[35] M. Wang, M. Ford, H. Phan, J. Coughlin, T. Q. Nguyen, G. C. Bazan, Chem. Commun. 2016, 52, 3207-3210.

[36] A. C. Stuart, J. R. Tumbleston, H. Zhou, W. Li, S. Liu, H. Ade, W. You, J. Am. Chem. Soc. 2013, 135, 1806-1815.

[37] A. Giovannitti, I. P. Maria, D. Hanifi, M. J. Donahue, D. Bryant, K. J. Barth, B. E. Makdah, A. Savva, D. Moia, M. Zetek, P. R. F. Barnes, O. G. Reid, S. Inal, G. Rumbles, G. G. Malliaras, J. Nelson, J. Rivnay, I. McCulloch, Chem. Mater. 2018, 30, 2945-2953.

[38] B. Meng, H. Song, X. Chen, Z. Xie, J. Liu, L. Wang, Macromolecules 2015, 48, 4357-4363.

[39] S. Zhang, J. Gao, W. Wang, C. Zhan, S. Xiao, Z. Shi, W. You, ACS Appl. Energy Mater. 2018, 1, 1276-1285.

[40] A. Giovannitti, D.-T. Sbircea, S. Inal, C. B. Nielsen, E. Bandiello, D. A. Hanifi, M. Sessolo, G. G. Malliaras, I. McCulloch, J. Rivnay, Proc. Natl. Acad. Sci. 2016, 113, 12017-12022.

[41] N. Wang, A. Yang, Y. Fu, Y. Li, F. Yan, Acc. Chem. Res. 2019, 52, 277-287.

[42] L. R. Savagian, A. M. Österholm, J. F. Ponder, K. J. Barth, J. Rivnay, J. R. Reynolds, Adv. Mater. 2018, 30, 1804647.

[43] C. B. Nielsen, A. Giovannitti, D. T. Sbircea, E. Bandiello, M. R. Niazi, D. A. Hanifi, M. Sessolo, A. Amassian, G. G. 
Malliaras, J. Rivnay, I. McCulloch, J. Am. Chem. Soc. 2016, 138, 10252-10259.

[44] C. K. Song, B. J. Eckstein, T. L. D. Tam, L. Trahey, T. J. Marks, ACS Appl. Mater. Interfaces 2014, 6, 19347-19354.

[45] S. S. Gunathilake, H. D. Magurudeniya, P. Huang, H. Nguyen, E. A. Rainbolt, M. C. Stefan, M. C. Biewer, Polym. Chem. 2013, 4, 5216.

[46] C. M. Cardona, W. Li, A. E. Kaifer, D. Stockdale, G. C. Bazan, Adv. Mater. 2011, 23, 2367-2371.

[47] J. Heinze, B. A. Frontana-Uribe, S. Ludwigs, Chem. Rev. 2010, 110, 4724-4771.

[48] L. Q. Flagg, C. G. Bischak, J. W. Onorato, R. B. Rashid, C. K. Luscombe, D. S. Ginger, J. Am. Chem. Soc. 2019, 141, 4345-4354.

[49] T. H. Lee, K. Y. Wu, T. Y. Lin, J. S. Wu, C. L. Wang, C. S. Hsu, Macromolecules 2013, 46, 7687-7695.

[50] X. Strakosas, G. G. Malliaras, C. Tassone, B. A. Collins, D. M. Delongchamp, J. Rivnay, S. Inal, M. Sessolo, E. Stavrinidou, Nat. Commun. 2016, 7, 1-9.

[51] S. Inal, G. G. Malliaras, J. Rivnay, Nat. Commun. 2017, 8, 1767.

[52] L. Q. Flagg, C. G. Bischak, J. W. Onorato, R. B. Rashid, C. K. Luscombe, D. S. Ginger, J. Am. Chem. Soc. 2019, jacs.8b12640.

[53] T. F. Otero, A. H. Grande, J. Rodríguez, 1997, 101, 85258533. 
Entry for the Table of Contents (Please choose one layout)

Layout 1:

\section{FULL PAPER}

We have designed and synthesised, by direct arylation, a series of glycolated thiophenetetrafluorophenylene copolymers as active materials for OECTs. The materials have been investigated electrochemically, optically and in the solid state. We have examined the most promising of these materials for use in biological sensing applications as an OECT active channel material and achieved promising $\mathrm{mA}$ transconductance.

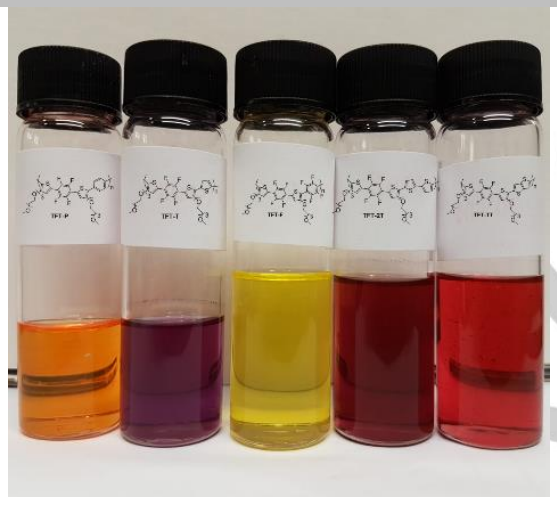

Zachary S. Parr ${ }^{\text {alt }}$, Roman Halaksa ${ }^{[a],[b]+}$, Peter A. Finn ${ }^{[a]}$, Reem B. Rashid ${ }^{[c]}$, Alexander Kovalenko[b], Martin Weiter ${ }^{[b]}$, Jonathan Rivnay ${ }^{[c]}$, Jozef Krajčovič ${ }^{[b]}$, Christian $B$. Nielsen ${ }^{[a]^{*}}$

Page No. - Page No.

Glycolated ThiopheneTetrafluorophenylene Copolymers for Bioelectronic Applications: Synthesis by Direct Heteroarylation Polymerisation

\section{Layout 2:}

Text for Table of Contents

Author(s), Corresponding Author(s)*

Page No. - Page No.

Title 